\title{
Enhanced Recovery After Surgery (ERAS): New Concepts in the Perioperative Management of Gynecologic Surgery
}

\section{Programa Enhanced Recovery After Surgery (ERAS): novos conceitos de manejo perioperatório em Cirurgia Ginecológica}

\author{
Agnaldo Lopes da Silva Filho ${ }^{1,2}$ Aline Evangelista Santiago ${ }^{1}$ Sophie Françoise Mauricette Derchain ${ }^{3}$ \\ Jesus Paula Carvalho ${ }^{4}$ \\ 1 Universidade Estadual Paulista “Júlio de Mesquita Filho," Botucatu, \\ SP, Brazil \\ 2 Universidade Federal de Minas Gerais, Belo Horizonte, MG, Brazil \\ 3 Universidade Estadual de Campinas, Campinas, SP, Brazil \\ ${ }^{4}$ Universidade de São Paulo, São Paulo, SP, Brazil \\ Rev Bras Ginecol Obstet 2018;40:433-436.
}

\section{What is ERAS?}

The Enhanced Recovery After Surgery (ERAS) program is a paradigm shift from traditional perioperative management initiated by Kehlet in $1997^{1}$ as a multidisciplinary approach to the care of the surgical patient. ${ }^{1-3}$ The program is based on perioperative medical optimization, including preoperative counseling, pain relief, carbohydrate loading, thromboembolism prophylaxis, standard anesthetic protocol and intraoperative fluid, recovery of normal gastrointestinal function, and early mobilization (-Table $\mathbf{1}$ ). The primary goal of the protocol is to minimize the response to the stress of the operation by maintaining homeostasis, avoiding catabolism with consequent loss of protein and muscle strength, and cellular dysfunction. $^{3}$

The main objectives of the ERAS program are to accelerate functional recovery, improve postoperative outcomes, shorten the length of stay (LOS) in the hospital, reduce the overall health care costs, and improve the satisfaction of the patients without increasing complications and/or hospital readmission rates. ${ }^{4}$ The ERAS protocols resulted in a $30 \%$ to $50 \%$ reduction in the LOS and similar reductions in complications, as well as lower costs and readmission rates. ${ }^{3}$ The protocols were developed for colorectal surgery, and variations are being adopted for surgical procedures of various specialties, including Gynecology. ${ }^{5,6}$

The ERAS Society is an international nonprofit professional society that promotes, develops, and implements ERAS programs, publishes updated guidelines for many operations, and was officially registered in 2010 in Sweden (http://erassociety.org). Its mission is to develop periopera-

Address for correspondence Agnaldo Lopes da Silva Filho, MD, 10.1055/s-0038-1668581. PhD, Avenida Professor Alfredo ISSN 0100-7203.

Balena, 190, 30130-100, Belo

Horizonte, MG, Brasil

(e-mail: agnaldo.ufmg@gmail.com). tive care and to improve recovery through research, education, auditing and implementation of evidence-based practices. Throughout its history, the ERAS Society has developed and published numerous evidence-based protocols and implementation programs worldwide to enhance recovery after surgery. This society conducts structured implementation programs that are currently in use in more than 20 countries. The ERAS Society group published in 2016 the guidelines for pre- and intraoperative care in gynecologic oncology surgery. ${ }^{7,8}$ In 2005 , the Department of Surgery of The Faculty of Medical Sciences of Universidade Federal do Mato Grosso, Brazil, adapted the ERAS program to our reality and created the Accelerating the Total Postoperative Recovery (ACERTO, in the Portuguese acronym) project. The application of the ACERTO multimodal protocol determined a significant improvement in morbidity and mortality in general surgery. ${ }^{9}$

\section{Why should an ERAS pathway be adopted in gynecologic surgeries?}

Most of the data on the ERAS program that is available in the literature refers to colorectal surgeries. Variations of the protocol are being adopted for gynecologic procedures despite the limited population and procedure-specific outcome data. ${ }^{5}$ Studies comparing the ERAS program to conventional practices in gynecologic surgery have shown a faster patient recovery, as well as a significant reduction in the LOS without an increase in readmission rates and complications in patients submitted to the practices recommended by the program..$^{2-4,10}$ In addition, the incidences of urgent clinic

Copyright (C) 2018 by Thieme Revinter Publicações Ltda, Rio de Janeiro, Brazil
License terms

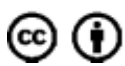


Table 1 Enhanced Recovery After Surgery (ERAS) program principles

\begin{tabular}{|c|c|c|}
\hline \multicolumn{3}{|c|}{ Enhanced Recovery After Surgery (ERAS) program } \\
\hline What does it promote? & Why should it be implemented? & $\begin{array}{l}\text { What is necessary for the implemen- } \\
\text { tation? }\end{array}$ \\
\hline $\begin{array}{l}\text { - Minimization of the stress response to } \\
\text { the operation by controlling the peri- } \\
\text { operative physiology } \\
\text { - Operative medical optimization: pre- } \\
\text { operative counseling, pain relief, car- } \\
\text { bohydrate loading, thromboembo- } \\
\text { lism prophylaxis, standard anesthetic } \\
\text { protocol and intraoperative fluid, } \\
\text { recovery of normal gastrointestinal } \\
\text { function, and early mobilization }\end{array}$ & $\begin{array}{l}\text { - Shorter length of hospital stay } \\
\text { - No increase in readmissions and/or } \\
\text { reoperations and/or complications } \\
\text { rates } \\
\text { - Faster and safer patient recovery } \\
\text { - Improved quality of life and patient } \\
\text { satisfaction } \\
\text { - Reduction in overall healthcare costs }\end{array}$ & $\begin{array}{l}\text { - Program coordinator (doctor/nurse) } \\
\text { - Involvement of all units dealing with } \\
\text { the surgical patient } \\
\text { - Multidisciplinary team working } \\
\text { together around the patient } \\
\text { - Multimodal approach to resolving } \\
\text { issues that delay recovery and cause } \\
\text { complications } \\
\text { - Scientific, evidence-based approach to } \\
\text { care protocols } \\
\text { - Change in management through } \\
\text { interactive and continuous audits } \\
\text { - Whenever possible, minimally invasive } \\
\text { surgery }\end{array}$ \\
\hline
\end{tabular}

Source: Adapted from Kehlet (1997) ${ }^{1}$ and Carey and Molder (2018). ${ }^{2}$

and emergency room visits, readmissions, and reoperations within 90 days of the surgery were similar for patients who were discharged on the day of the surgery compared with those admitted for more than 24 hours. ${ }^{11}$

Introducing the ERAS protocol for abdominal hysterectomy reduced the LOS without increasing complications or readmissions. ${ }^{10}$ For benign vaginal hysterectomies, ERAS has been associated with a reduction in the LOS of $51.6 \%$, and it enables more women to be discharged within 24 hours, with no increase in patient readmissions rates. ${ }^{12}$ Establishing the program for vaginal hysterectomy also resulted in a reduction in costs, coupled with increased patient satisfaction and no rise in morbidity. ${ }^{13}$

In Urogynecology, ERAS implementation has been associated with a greater proportion of same-day discharges and high patient satisfaction, but with slightly increased hospital readmissions within 30 days. ${ }^{5}$ The implementation of ERAS protocols in gynecologic surgeries has been associated with a substantial reduction in the administration of intravenous fluids and morphine, as well as a reduction in the LOS in open procedures associated with improved patient satisfaction and decreased hospital costs. ${ }^{14}$

Regarding minimally invasive surgeries (MISs), increased American Society of Anesthesiologists (ASA) physical status, being African American, and increased length of procedure were significantly associated with readmissions after laparoscopic hysterectomies for benign and malignant conditions performed following an ERAS pathway. ${ }^{15}$ Even in gynecologic oncology MISs in, ERAS is associated with a decreased LOS without increases in morbidity or readmission rates. ${ }^{11}$

The implementation of ERAS protocols for women undergoing major gynecologic surgery has been associated with a substantial decrease in intravenous fluid and morphine administration combined with a reduction in the LOS, improved patient satisfaction, and decreased hospital costs. ${ }^{14}$ Despite the lack of high quality studies evaluating the benefits of enhanced recovery programs in comparison to conventional care for gynecologic cancer patients, this approach is considered a safe perioperative management strategy. The LOS is reduced, without affecting the rates of complications or readmission., ${ }^{6,16-18}$

The ERAS principles are applied across all surgical specialties, and ongoing innovation must continue to enable the processes to improve. ${ }^{3}$ A successful ERAS program can lead to a reduction in overall healthcare costs, faster and safer recovery, and improved quality of life and patient satisfaction. In addition, for patients with gynecologic cancer, returning to or getting close to the baseline physiological level enables the accomplishment of the planned adjuvant therapies without delay, resulting in better oncologic outcomes. ${ }^{4}$

\section{How should an ERAS program be implemented?}

The essential aspect in changing the practice and implementing an ERAS pathway is forming a team composed of key individuals from each involved unit. $^{3}$ As illustrated in - Table 1, the ERAS program has several principles. ${ }^{2,3}$ The approach to the care of the surgical patient through the various parts of the hospital must be multimodal and multidisciplinary. ${ }^{3}$ The process of implementation of an ERAS program involves a team consisting of surgeons, anesthetists, an ERAS coordinator (often a nurse or a physician assistant), nurses, dieticians, and physiotherapists from units that care for the surgical patient. ${ }^{3}$ No single element by itself will improve the outcomes of surgery. Adherence to the program is crucial, and continuous auditing of the care process enables the team to have a comprehensive view of the patient outcomes. ${ }^{3}$ Minimally invasive surgery is a vital component of an ERAS program, and should be the preferred surgical approach whenever possible. ${ }^{2}$

The program brings together best practices, organization of care and clinical management. ${ }^{6}$ The care protocol is based on published evidence, and it is important to 
implement additional changes in light of new evidence. An important goal for the ERAS Society is to build a network of hospitals around the world. Successful implementation of an ERAS program requires a multidisciplinary team effort and active participation of the patient in the goal-oriented functional recovery program. ${ }^{4}$ The ERAS program focuses on patients who actively participate in their own recovery process, and ensures they receive adequate postoperative care.

The implementation ERAS in gynecologic surgery involves four essential stages: the preadmission, preoperative, intraoperative, and postoperative stages. ${ }^{2}$ The strategies include preadmission counseling, avoidance of preoperative bowel preparation, use of opioid-sparing multimodal perioperative analgesia (including locoregional analgesia), intraoperative goal-directed fluid therapy, and avoidance of routine use of nasogastric tubes, drains and/or catheters. ${ }^{4}$ Postoperatively, it is important to encourage early feeding, early mobilization, timely removal of tubes and drains, if present, and opioidsparing analgesia regimens.

The recommendations of the perioperative enhanced recovery pathway for gynecologic surgeries are shown in - Table 2. . $^{2,7,8,17}$ Smoking and alcohol consumption (alcohol abusers) should cease four weeks before surgery. Anemia should be actively identified, investigated, and corrected preoperatively. Mechanical bowel preparation should

Table 2 Main recommendations of the perioperative enhanced recovery pathway for gynecologic surgeries

\begin{tabular}{|c|c|c|}
\hline \multicolumn{3}{|c|}{ Enhanced Recovery After Surgery (ERAS) program recommendations for gynecologic surgeries } \\
\hline \multirow[t]{2}{*}{$\begin{array}{l}\text { Preadmission } \\
\text { stage }\end{array}$} & Prevention of complications & $\begin{array}{l}\text { Appropriate preoperative risk stratification, timely risk modifi- } \\
\text { cation, and medical optimization have to be performed. } \\
\text { Screen and treat anemia }\end{array}$ \\
\hline & Counseling & Preoperative counseling of patients and caregivers \\
\hline \multirow[t]{4}{*}{$\begin{array}{l}\text { Preoperative } \\
\text { stage }\end{array}$} & Bowel preparation & $\begin{array}{l}\text { Elimination of mechanical bowel preparation and rectal enema } \\
\text { for most procedures }\end{array}$ \\
\hline & Diet & $\begin{array}{l}\text { No solids after midnight; clear liquid diet } 2-4 \text { hours before } \\
\text { surgery; } \\
100 \text {-g carbohydrate-loaded drink the night before surgery; and a } \\
50 \text {-g carbohydrate-loaded drink } 2-4 \text { hours before surgery }\end{array}$ \\
\hline & Premedication & $\begin{array}{l}\text { Avoid long- or short-term sedative agents } \\
\text { (Tramadol ER, Pregabalin, Celecoxib, Acetaminophen IV) }\end{array}$ \\
\hline & IVF therapy & Saline lock until going to the OR \\
\hline \multirow[t]{4}{*}{$\begin{array}{l}\text { Intraoperative } \\
\text { stage }\end{array}$} & $\begin{array}{l}\text { Analgesia immediately before going } \\
\text { to the OR }\end{array}$ & $\begin{array}{l}\text { Acetaminophen } 1,000 \mathrm{mg} \text { PO; Gabapentin } 600-1,200 \mathrm{mg} \text { PO } \\
\text { once or Pregabalin } 100-300 \mathrm{mg} \text { PO once; Celecoxib } 200- \\
400 \mathrm{mg} \text { PO once }\end{array}$ \\
\hline & Nausea and vomiting prophylaxis & $\begin{array}{l}\text { Scopolamine transdermal patch } 2 \text { hours preoperatively; Dexa- } \\
\text { methasone } 4 \mathrm{mg} \text { IV once at induction }\end{array}$ \\
\hline & Analgesia & $\begin{array}{l}\text { Total intravenous anesthesia; regional anesthesia if appropriate; } \\
\text { Acetaminophen 1,000 mg IV once (if not oral); local wound } \\
\text { infiltration: preincisional or postincisional bupivacaine hydro- } \\
\text { chloride or postincision liposomal bupivacaine }\end{array}$ \\
\hline & Fluid balance & $\begin{array}{l}\text { Goal-directed fluid therapy with a net zero balance at the end of } \\
\text { the surgical case; Lactated Ringer's over normal saline for } \\
\text { electrolyte balance }\end{array}$ \\
\hline \multirow{7}{*}{$\begin{array}{l}\text { Postoperative } \\
\text { stage }\end{array}$} & IVF therapy & IVF $40 \mathrm{ml} / \mathrm{h}$; saline lock when tolerating $500 \mathrm{ml}$ oral \\
\hline & Analgesia & $\begin{array}{l}\text { Opioid-sparing analgesia; Acetaminophen or Ibuprofen; Prega- } \\
\text { balin, } 75 \text { mg every } 12 \text { hours (for } 48 \text { hours) }\end{array}$ \\
\hline & Nausea and vomiting management & $\begin{array}{l}\text { Ondansetron } 4 \text { mg PO every } 6 \text { hours prn nausea and vomiting, } \\
\text { or Prochlorperazine } 10 \mathrm{mg} \text { IV every } 6 \text { hour prn nausea and } \\
\text { vomiting }\end{array}$ \\
\hline & Diet & Regular diet on POD0; oral hydration; gum chewing \\
\hline & Foley catheter & Remove on POD1 \\
\hline & Activity & $\begin{array}{l}\text { Ambulate } 8 \text { times a day; eat all meals sitting in a chair; stay out of } \\
\text { bed } 8 \text { hours a day }\end{array}$ \\
\hline & Transfusion & Restrictive; only for hemoglobin level $>7$ \\
\hline
\end{tabular}

Abbreviations: ER, endorectal; IV, intravenous; IVF, intravenous fluids; OR, operating room; PO, postoperative; POD, postoperative day; PRN, pro re nata (when necessary).

Source: Adapted from Miralpeix et al. (2015); ${ }^{4}$ Nelson et al. (2016); ${ }^{7,8}$ Ljungqvist et al. (2017); ${ }^{3}$ and Carey and Molder (2018). ${ }^{2}$ 
not be used routinely even when bowel resection is planned. The intraoperative prevention of intraoperative hypothermia with suitable active warming devices should be used routinely. Very restrictive or liberal fluid regimes should be avoided in favor of euvolemia. The intraoperative stage recommendations include the standard anesthetic protocol, avoidance of nasogastric tubes or removal at the end of surgery, and infusion of local anesthetic (bupivacaine) in the wound (deep and superficial injections) prior to closure. $^{4,7}$

The prophylaxis against thromboembolism includes wellfitting compression stockings and intermittent pneumatic compression. Extended prophylaxis (28 days) should be given to patients after laparotomy for abdominal or pelvic malignancies. The key postoperative protocol elements are early feeding (limiting the administration of intravenous fluids when the patient tolerates oral intake greater than $500 \mathrm{ml}$ ), early mobilization and opioid-sparing analgesia. A multimodal approach to postoperative nausea and vomiting with antiemetic agents should be used for patients undergoing gynecologic procedures. The patient should ambulate 8 times per day, have all meals sitting in a chair, and stay out of bed at least 8 hours per day. 4,7

\section{Final considerations}

The implementation of the ERAS program represents a paradigm change in the perioperative management of the surgical patient, and is a multidisciplinary approach based on scientific evidence management. ${ }^{3}$ The program is clinically effective and has impacts on the outcomes of the patients, offering a safe, high-quality and cost-effective/cost-saving perioperative care. Therefore, the ERAS program should become the standard practice for all women undergoing elective gynecologic surgeries. ${ }^{16}$ Implementation challenges have been attributed to a variety of contextual factors, such as perceived lack of resources and resistance to change among providers. The number and combination of ERAS elements varied considerably across the studies. In Brazil, the challenge is to define strategies to adopt perioperative enhanced recovery programs in different scenarios. Compliance by the staff and the patients to the protocol elements of the ERAS is crucial to ensure a well-established and successful program.

\section{Conflicts of interest}

The authors have no conflicts of interest to disclose.

\section{References}

1 Kehlet H. Multimodal approach to control postoperative pathophysiology and rehabilitation. Br J Anaesth 1997;78(05):606-617. Doi: 10.1093/bja/78.5.606

2 Carey ET, Moulder JK. Perioperative management and implementation of enhanced recovery programs in gynecologic surgery for benign indications. Obstet Gynecol 2018;132(01):137-146. Doi: 10.1097/AOG.0000000000002696
3 Ljungqvist O, Scott M, Fearon KC. Enhanced recovery after surgery: a review. JAMA Surg 2017;152(03):292-298. Doi: 10.1001/ jamasurg.2016.4952

4 Miralpeix E, Nick AM, Meyer LA, et al. A call for new standard of care in perioperative gynecologic oncology practice: Impact of enhanced recovery after surgery (ERAS) programs. Gynecol Oncol 2016;141(02):371-378. Doi: 10.1016/j.ygyno.2016.02.019

5 Carter-Brooks CM, Du AL, Ruppert KM, Romanova AL, Zyczynski HM. Implementation of an Urogynecology-Specific Enhanced Recovery After Surgery (ERAS) Pathway. [published on line Jun 15, 2018]Am J Obstet Gynecol 2018:S0002-9378(18)30496-4. Doi: 10.1016/j.ajog.2018.06.009

6 Myriokefalitaki E, Smith M, Ahmed AS. Implementation of enhanced recovery after surgery (ERAS) in gynaecological oncology. Arch Gynecol Obstet 2016;294(01):137-143. Doi: 10.1007| s00404-015-3934-4

7 Nelson G, Altman AD, Nick A, et al. Guidelines for pre- and intraoperative care in gynecologic/oncology surgery: Enhanced Recovery After Surgery (ERAS $\left.{ }^{\circledR}\right)$ Society recommendations-Part I. Gynecol Oncol 2016;140(02):313-322. Doi: 10.1016/j.ygyno.2015.11.015

8 Nelson G, Altman AD, Nick A, et al. Guidelines for postoperative care in gynecologic/oncology surgery: Enhanced Recovery After Surgery (ERAS $®)$ Society recommendations-Part II. Gynecol Oncol 2016;140(02):323-332. Doi: 10.1016/j.ygyno.2015.12.019

9 Bicudo-Salomão A, Meireles MB, Caporossi C, Crotti PL, de AguilarNascimento JE. Impact of the ACERTO project in the postoperative morbi-mortality in a university hospital. Rev Col Bras Cir 2011;38 (01):3-10. Doi: 10.1590/S0100-69912011000100002

10 Wijk L, Franzen K, Ljungqvist O, Nilsson K. Implementing a structured Enhanced Recovery After Surgery (ERAS) protocol reduces length of stay after abdominal hysterectomy. Acta Obstet Gynecol Scand 2014;93(08):749-756. Doi: 10.1111/aogs.12423

11 Lambaudie E, de Nonneville A, Brun C, et al. Enhanced recovery after surgery program in Gynaecologic Oncological surgery in a minimally invasive techniques expert center. BMC Surg 2017;17 (01):136. Doi: 10.1186/s12893-017-0332-9

12 Yoong W, Sivashanmugarajan V, Relph S, et al; Enhanced Recovery After Surgery (ERAS) Team for Gynaecology and Anaesthesia. Can enhanced recovery pathways improve outcomes of vaginal hysterectomy? Cohort control study. J Minim Invasive Gynecol 2014; 21(01):83-89. Doi: 10.1016/j.jmig.2013.06.007

13 Relph S, Bell A, Sivashanmugarajan V, et al. Cost effectiveness of enhanced recovery after surgery programme for vaginal hysterectomy: a comparison of pre and post-implementation expenditures. Int J Health Plann Manage 2014;29(04):399-406. Doi: 10.1002/hpm.2182

14 Modesitt SC, Sarosiek BM, Trowbridge ER, et al. Enhanced recovery implementation in major gynecologic surgeries: effect of care standardization. Obstet Gynecol 2016;128(03):457-466. Doi: 10.1097/AOG.0000000000001555

15 Keil DS, Schiff LD, Carey ET, et al. Predictors of admission after the implementation of an Enhanced Recovery After Surgery pathway for minimally invasive gynecologic surgery. [published on line Apr 11, 2018]Anesth Analg 2018. Doi: 10.1213/ANE.0000000000003339

16 Royal College of Obstetricians \& Gynaecologists. Enhanced Recovery in Gynaecology. London: RCOG; 2013. Scientific Impact Paper 36. https://www.rcog.org.uk/globalassets/documents/guidelines/ scientific-impact-papers/sip_36.pdf. Accessed March 10, 2017

17 Nelson G, Kalogera E, Dowdy SC. Enhanced recovery pathways in gynecologic oncology. Gynecol Oncol 2014;135(03):586-594. Doi: 10.1016/j.ygyno.2014.10.006

18 Lv D, Wang X, Shi G. Perioperative enhanced recovery programmes for gynaecological cancer patients. Cochrane Database Syst Rev 2010;(06):CD008239. Doi: 10.1002/14651858.CD008239.pub2 